\title{
Incorporating Brahman Genetics in the Cow Herd to Alleviate Heat Stress ${ }^{1}$
}

\author{
Kaitlyn Sarlo Davila, Heather Hamblen, Serdal Dikmen, Peter Hansen, Todd Thrift, and Raluca \\ Mateescu²
}

\section{Introduction}

The hot and humid climate of Florida makes beef cattle production a challenge. Cattle are maintained on extensive pasture systems. Therefore, the implementation of environmental modifications to alleviate heat stress is nearly impossible. Instead, producers must select cattle that are adapted to these conditions. Several breeds of cattle are adapted to these conditions including Bos indicus breeds (e.g., Brahman), Bos indicus-influenced breeds (e.g., Brangus or Beefmaster), and even tropically adapted Bos taurus breeds (e.g., Senepol). Thus, incorporating Brahman genetics into the cow herd can alleviate heat stress.

\section{Brahman Adaptation}

Bos indicus ("Zebu" cattle of Indian ancestry) breeds such as Brahman are better able to regulate their body temperature under heat stress than Bos taurus (cattle of European ancestry) breeds. There are several key adaptations of the hair and skin that allow Brahman cattle to thrive in hot and humid conditions. Brahman cattle have dark skin pigmentation that protects against UV damage from solar radiation. They also have short hair coats (on average, 10 mm shorter than Angus [Sarlo Davila et al. 2019]) that are light colored and reflect radiative heat, which help them to remain cooler. This short hair coat also helps cattle sweat more effectively. Most of the heat produced in beef cattle (almost 75\%-80\%) is lost through sweating when the sweat evaporates (Collier and Gebremedhin 2015). Short hair coats allow the sweat to evaporate quickly, while thick, dense hair coats trap the sweat against the body and prevent evaporation, which is the major heat loss mechanism for cattle. Brahman cattle also have a higher sweating rate, larger sweat glands, and more efficient blood flow from the body core to the skin than Bos taurus breeds (Finch 1985; Hansen 2004).

\section{Challenges Associated with Brahman Cattle}

While Brahman cattle excel at surviving in hot and humid conditions, the breed also faces several challenges. Brahman cattle tend to have more variation in tenderness and meat quality than most Bos taurus breeds. Weaned calves with a heavily Brahman appearance (greater than 50\%) often result in a lower price in the traditional marketing systems. While the prices vary based on year and market conditions, McCabe (2018) reported that on average, between 2010 and 2016, Brahman-influenced calves brought $\$ 4.57$ less per hundred weight than British calves when marketed through video auction. The Florida cow-calf producer should also note that Brahman females reach puberty later than Bos

1. This document is AN366, one of a series of the Department of Animal Sciences, UF/IFAS Extension. Original publication date October 2021. Visit the EDIS website at https://edis.ifas.ufl.edu for the currently supported version of this publication.

2. Kaitlyn Sarlo Davila, Ph.D. student, Department of Animal Sciences; Heather Hamblen, former Ph.D. student, Department of Animal Sciences, UF/ IFAS Extension; Serdal Dikmen, professor, Department of Animal Science, Uludag University, Bursa, Turkey; Peter Hansen, distinguished professor, reproductive biology, Department of Animal Sciences; Todd Thrift, associate professor, beef cattle management, Department of Animal Sciences; and Raluca Mateescu, professor, genomics, Department of Animal Sciences; UF/IFAS Extension, Gainesville, FL 32611.

The Institute of Food and Agricultural Sciences (IFAS) is an Equal Opportunity Institution authorized to provide research, educational information and other services

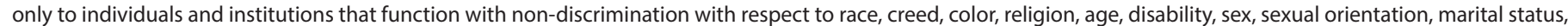

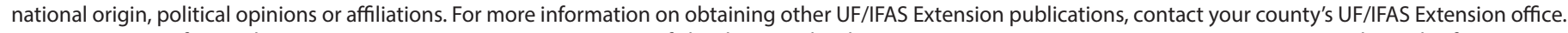
U.S. Department of Agriculture, UF/IFAS Extension Service, University of Florida, IFAS, Florida A \& M University Cooperative Extension Program, and Boards of County Commissioners Cooperating. Nick T. Place, dean for UF/IFAS Extension. 
taurus females. Randel (1990) reported that purebred Angus heifers reached puberty on average at 436 days of age. Brahman crossbred heifers reached puberty between 438 and 528 days of age, and purebred Brahman heifers did not reach puberty until 690 days of age. As a result, it takes purebred and crossbred Brahman heifers longer to produce a calf, which also means it takes longer for the producer to recoup some of the cost of developing a replacement heifer.

\section{Benefits of Crossbreeding with Brahman Cattle}

Many of the challenges associated with Brahman cattle can be overcome by utilizing crossbreeding. Hybrid vigor (the increased performance of crossbred animals compared to the average of their purebred parents) is maximized in crosses of Bos indicus and Bos taurus animals because they are more distantly related to each other. As a result of hybrid vigor, Bos indicus $\times$ Bos taurus crossbred females have $10 \%$ greater fertility, $5 \%$ greater calf survival, $12.5 \%$ greater weaning rate, $70 \mathrm{lb}$ greater calf weight at weaning, and $37 \%$ greater longevity compared to purebred females (Thrift and Thrift 2003). The other advantage of crossbreeding is breed complementarity (the desirable blending of characteristics from two breeds). When done correctly, blending of Bos taurus and Bos indicus breed traits can result in an animal that is both adapted to the Florida climate and acceptable to traditional marketing systems. One key to crossbreeding successfully is determining the optimum proportion of each breed.

\section{Recommended Brahman Incorporation}

The question then remains: when using crossbreeding, what is the optimum proportion of Brahman genetics to incorporate in the cow herd? Two studies utilized the multibreed herd at the University of Florida to answer this question. The multibreed herd consists of purebred Brahman and Angus cattle as well as crossbreds with varying proportions of the two breeds. Sarlo Davila et al. (2019) observed the internal body temperature of 335 heifers from the multibreed herd using an iButton thermometer placed inside a blank CIDR (a controlled internal drug release, often loaded with progesterone and used to synchronize ovulation in cattle before artificial insemination) and inserted vaginally into each animal. Cattle were observed under extreme heat stress conditions during the summer months in 2016 and 2017. The temperature humidity index is an indicator of heat stress and combines both temperature and humidity in a single measure. This index was used to characterize the environmental conditions when the internal temperature was measured. In this study, heat stress was considered extreme when the THI was between 84 and 86 for at least one hour. Figure 1 shows the body temperatures observed for cattle with different Brahman and Angus percentages. Cattle with as little as $25 \%$ Brahman influence were able to stay significantly cooler than purebred Angus cattle. However, only cattle that were $75 \%$ Brahman were able to stay as cool as the purebred Brahman. The relationship between Brahman percentage and internal body temperature was found to be linear. Every time that the animals experienced high heat stress, the percentage of Brahman genetics helped them to decrease their internal temperature. Figure 1 shows that, for every $25 \%$ increase in Brahman genetics, the average body temperature dropped by $0.23^{\circ} \mathrm{F}$.

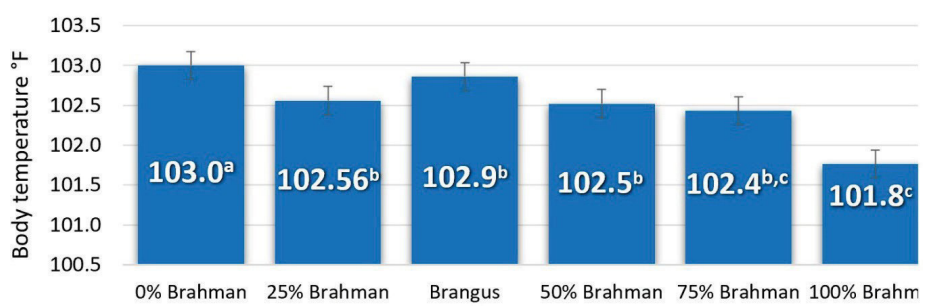

Figure 1. Relationship between breed composition and body temperature under heat stress. a-cBreed groups with differing letter superscripts are significantly different $(P<0.05)$. Remaining breed composition is Angus.

Credits: Adapted from Sarlo Davila et al. (2019)

While the slightly over $1^{\circ} \mathrm{F}$ body temperature difference between Angus and Brahman may not seem like a large difference, it is important to also take into account cattle behavior and activity during these periods of high heat stress when the internal body temperature was recorded. Dikmen et al. (2018) evaluated grazing behavior of cattle from the UF multibreed herd under extreme heat stress. Cattle were fitted with a GPS collar to track their movement across the pasture during the day. Purebred Brahman cattle spent significantly more time grazing in the pasture while purebred Angus cattle remained in the shade, not grazing, for most of the day. Angus cattle only grazed during the early morning, evening, and night while Brahman cattle grazed throughout the day. The greater the percentage of Brahman genetics cattle had, the more time they spent grazing. Therefore, Brahman cattle are able to stay cooler under hot conditions while still grazing.

\section{Conclusion}

Incorporating Brahman genetics into the cow herd alleviates heat stress. It is recommended that cattle be between $25 \%$ and $75 \%$ Brahman in order to be adapted to the hot, humid climate of Florida, although the degree of heat stress varies across the state. Cattle with least 25\% Brahman are 
able to remain cooler than purebred Bos taurus breeds, while cattle that are $75 \%$ Brahman perform comparably to purebred Brahmans. This a large range, and the optimal level of Brahman incorporation into the cow herd is a decision that must be made by each individual producer, taking into account the magnitude of heat stress in their location, the current production level of their herd, and the way in which they market their cattle. However, given the increase in productivity to hybrid vigor as well the alleviation of heat stress that results, crossbreeding with Brahman is highly recommended for cow-calf production in Florida.

\section{References}

Collier, R. J., and K. G. Gebremedhin. 2015. “Thermal Biology of Domestic Animals." Annu. Rev. Anim. Biosci. 3:513-532. doi:10.1146/annurev-animal-022114-110659.

Dikmen, S., R. G. Mateescu, M. A. Elzo, and P. J. Hansen. 2018. "Determination of the Optimum Contribution of Brahman Genetics in an Angus-Brahman Multibreed Herd for Regulation of Body Temperature during Hot Weather." J. Anim. Sci. 96:2175-2183. doi:10.1093/jas/sky133.

Finch, V. A. 1985. "Comparison of Non-Evaporative Heat Transfer in Different Cattle Breeds." Aust. J. Agric. Res. 36:497-508. doi:10.1071/AR9850497.

Hansen, P. J. 2004. "Physiological and Cellular Adaptations of Zebu Cattle to Thermal Stress." Anim. Repro. Sci. 82:349-360. doi:10.1016/j.anireprosci.2004.04.011.

McCabe, E. D. 2018. "Breed Trends and Effect of Breed on Sale Price of Lots of Beef Calves Marketed via Video Auction." Kansas State University.

Randel, R. D. 1990. "Unique Reproductive Traits of Brahman and Brahman Based Cows." Texas A\&M University Agrilife Extension.

Sarlo Davila, K. M., H. Hamblen, P. J. Hansen, S. Dikmen, P. A. Oltenacu, and R. G. Mateescu. 2019. "Genetic Parameters for Hair Characteristics and Core Body Temperature in a Multibreed Brahman-Angus Herd." J. Anim. Sci. doi:10.1093/jas/skz188.

Thrift, F. A., and T. A. Thrift. 2003. "Longevity Attributes of Bos indicus x Bos taurus Crossbred Cows." The Professional Animal Scientist 19(5): 329-341. 